\title{
Sistemas agroflorestais em áreas de agricultores familiares em Igarapé-Açu, Pará: caracterização florística, implantação e manejo
}

\author{
Thiago Almeida VIEIRA ${ }^{1}$, Leonilde dos Santos ROSA², Paulo César Silva VASCONCELOS³, Mônica Mota \\ dos SANTOS ${ }^{4}$, Rozi da Silva MODESTO5
}

\section{RESUMO}

Este trabalho objetivou avaliar os Sistemas Agroflorestais-SAF comerciais multiestratificados de agricultores familiares de Igarapé-Açu, bem como identificar as espécies que compõem os sistemas agroflorestais. A partir de entrevistas foram catalogadas as espécies de maior interesse dos agricultores familiares e por meio de inventário florístico foram avaliados os SAF produtivos. Os cultivos de pimenta-do-reino, mandioca, feijão, cupuaçu, caju, açaí, pupunha, mogno e o nim indiano foram os mais freqüentes pelos agricultores. Os SAF são manejados na sua maioria de forma tradicional.

PALAVRAS-CHAVE: Sistemas agroflorestais, Espécies agroflorestais, Agricultura familiar, Amazônia.

\section{Agroforestry systems in areas of smallholder agriculture in Igarapé-Açu, Pará: floristic characterization, implantation and management}

\section{ABSTRACT}

This paper aimed to evaluate the multistrata agroforestry systems of small farmers of Igarapé-Açu, as well as to identify the species that compose of they interest. Through interviews were listed the interest species of small farmers and from inventory floristic were evaluated the productive AFS. The species: pepper-of-kingdom, cassava, beans, cupuaçu, caju, açai palm, pupunha palm, mahogany and indian neem were the most cultivated by these farmers. Most of the AFS are managed in the traditional manner.

KEYWORDS: Agroforestry systems, Agroforestry species, Smallholder agriculture, Amazon.

1 Empresa de Assistência Técnica e Extensão Rural do Pará, EMATER-PA. Trav. Marcos Belicha, 16 Bom Pastor. CEP 68170-000 - Juruti, PA - Brasil. Telefone: (93) 35361216. e-mail: tavbelem@yahoo.com.br

2 UFRA. e-mail: leonilders@yahoo.com.br

${ }^{3}$ UFRA. e-mail: pcvasc@yahoo.com.br

4 moniflorest@yahoo.com.

5 rozi2064@yahoo.com. 


\section{INTRODUÇÃO}

Dentre as diferentes formas de Sistemas Agroflorestais - SAF nas regiōes tropicais são destacados os sistemas taungya, silvipastoris, quintais agroflorestais e os sistemas multiestratificados comerciais, sendo estes dois últimos bastante praticados na Amazônia. Os sistemas multiestratificados permitem que os agricultores familiares possam obter renda de diferentes espécies e produtos ao longo do ano.

$\mathrm{Na}$ Amazônia, é comum o cultivo de espécies frutíferas em SAF comerciais multiestratificados. Estas espécies, em geral, são cultivadas por agricultores familiares com fins comerciais e para sua subsistência.

Apesar dessas vantagens, há carência de informaçōes com relação ao manejo dos SAF, à silvicultura das espécies que compõem os mesmos, ao desenho e ao arranjo desses sistemas por parte dos agricultores familiares, os quais, na maioria das vezes têm mais conhecimento acerca dos cultivos agrícolas. Segundo Bentes-Gama (2003), a falta do monitoramento contínuo de espécies arbóreas em SAF, ao longo do tempo, é um dos entraves que impede o avanço do conhecimento acerca do desempenho produtivo nesses sistemas. Isso leva à falta de domínio dos processos e não favorece a difusão dos resultados obtidos destes sistemas para os produtores. Outro fator limitante na adoção destes sistemas é a falta de capital próprio e de financiamentos para os consórcios de interesse do agricultor familiar.

Este trabalho teve o objetivo de avaliar os SAF comerciais multiestratificados de agricultores familiares de Igarapé-Açu e identificar espécies de interesse deste agricultor.

\section{MATERIAL E MÉTODOS}

O estudo foi realizado no Município de Igarapé-Açu (01 $07^{\circ} 33^{\prime \prime}$ S e 47 37' 27” W), localizado na Microrregião Bragantina, no Nordeste do Pará, a $105 \mathrm{~km}$ da capital Belém, PA.

A avaliação dos SAF multiestratificados comerciais produtivos no município de estudo foi realizada com o auxílio de entrevista semi-estruturada (Anexo 1), observação direta, registro fotográfico e, inventário florístico (censo) dos componentes arbóreos.

Essa pesquisa, deste a coleta de dados por meio de entrevistas até por meio do inventário florístico, compreendeu o período de setembro de 2004 a dezembro de 2005. No inventário foram analisados os seguintes parâmetros: a área dos SAF, espaçamento entre plantas, altura total, diâmetro da base do caule (DAB), diâmetro altura do peito (DAP) e diâmetro de copa (DAC) das espécies lenhosas. No caso das palmeiras foram feitas apenas avaliação do crescimento em altura e diâmetro da base do caule.
Os SAF avaliados pertencem a 16 famílias de agricultores familiares. Esses agricultores foram identificados por meio de informaçōes dos técnicos da Empresa de Assistência Técnica e Extensão Rural do Pará (EMATER-PA), escritório local do município e dos funcionários da Fazenda Escola de IgarapéAçu da Universidade Federal Rural da Amazônia, sendo que não foram considerados neste estudo, os SAF resultantes de projetos de pesquisa e as espécies de ciclo curto e semi-perenes, devido o ciclo de vida das mesmas.

\section{RESULTADOS E DISCUSSÃO}

\section{ESPÉCIES CULTIVADAS}

Neste estudo foram identificadas 38 espécies (7 temporárias e 31 permanentes) cultivadas em SAF, pelos agricultores da área de estudo (Tabela 1). A preferência dos agricultores da área de estudo pelas culturas anuais e pelas espécies permanentes frutíferas, provavelmente, está relacionada com a segurança alimentar da família e com as demandas do mercado local.

A preferência por culturas permanentes especialmente por frutíferas também foi constatada por Franke et al. (1998), em estudos realizados em SAF estabelecidos em áreas de agricultores familiares do Acre. O cultivo das frutíferas, segundo estes autores, tinha como finalidade principal a venda dos frutos e a subsistência das famílias locais.

Tabela 1 - Freqüência das espécies cultivadas nos sistemas agroflorestais implantados por agricultores familiares da área de estudo.

\begin{tabular}{llll}
\hline Nome Vulgar & Nome Científico & Fr (\%) & Finalidade \\
\hline Temporárias & & & \\
\hline Mandioca & Manihot esculenta Crantz & 28,1 & A, C \\
Feijão caupi & Vigna sp & 25 & A, C \\
\hline Abacaxi & Ananás comosus L. & 3,1 & C \\
\hline Arroz & Oriza sativa L. & 3,1 & A \\
\hline Batata doce & Ipomoea batatas (L.) LAM. & 3,1 & A \\
\hline Jerimum & Curcubita sp. & 3,1 & A \\
\hline Pimenta-de-cheiro & Capsicum sp. & 3,1 & A \\
\hline Permanentes & & & \\
\hline Pimenta-do-reino & Piper nigrum L. & 50 & C \\
\hline Cupuaçu & Theobroma grandiflorum & 34,4 & A, C \\
\hline Caju & Schum. & 21,9 & A, C \\
\hline Açaí & Anacardium occidentale L. & 18,8 & A \\
\hline Maracujá & Euterpe oleracea Mart. & 18,8 & C \\
\hline Mogno & Passiflora sp & 18,8 & C \\
\hline Pupunha & Swietenia macrophylla King. & 18,8 & A, C \\
\hline & Bactris gasipaes H.B.K. & \\
\hline
\end{tabular}




\begin{tabular}{|c|c|c|c|}
\hline Coco & Coccus nucifera L. & 15,6 & C \\
\hline Nim indiano & Azadirachta indica A. Juss. & 15,6 & C \\
\hline Graviola & Annona muricata L. & 12,5 & C \\
\hline Urucum & Bixa orellana L. & 12,5 & C \\
\hline Andiroba & Carapa guianensis Aubl. & 9,4 & C \\
\hline Muruci & Byrsonima carssifolia H.B.K. & 9,4 & C \\
\hline Teça & Tectona grandis Lf. & 9,4 & C \\
\hline Acacia mangium & Acacia mangium WILLD & 6,3 & C \\
\hline Banana & Musa sp & 6,3 & $A, C$ \\
\hline Laranja & Citrus sinensis (L.) Osb. & 6,3 & $A, C$ \\
\hline Limão & Citrus sp. & 6,3 & C \\
\hline Mamão & Carica papaya L. & 3,1 & A \\
\hline Abacate & Persea americana Mill. & 3,1 & A \\
\hline Bacabi & Oenocarpus minor Mart. & 3,1 & $A$ \\
\hline Cacau & Theobroma cacao L. & 3,1 & C \\
\hline Cedro & Cedrela odorata L. & 3,1 & C \\
\hline Cumaru & Dipterix odorata (Aubl.) Willd & 3,1 & C \\
\hline Ingá & Inga edulis Mart. & 3,1 & A \\
\hline Ipê & Tabebuia serratifolia Rolfe & 3,1 & C \\
\hline Manga & Mangifera indica L. & 3,1 & $A$ \\
\hline Paricá & $\begin{array}{l}\text { Schizolobium amazonicum } \\
\text { (Huber) Ducke }\end{array}$ & 3,1 & C \\
\hline Quaruba & Vochysia sp. & 3,1 & C \\
\hline Sumaúma & Ceiba pentandra (L.) Gaertn & 3,1 & C \\
\hline Tachi & Triplaris surinamensis Cham. & 3,1 & C \\
\hline
\end{tabular}

Nota: Fr (\%): freqüência relativa expressa em porcentagem. A: Autoconsumação; C: Comercialização.

Ao se analisar a Tabela 1, nota-se que dentre as espécies temporárias anuais, mandioca (Manihot esculenta) é a que mais se destaca nos sistemas agroflorestais identificados, além do feijāo (Vigna sp.), espécie bastante cultivada e que também tem um papel importante na segurança alimentar de agricultores familiares.

Apesar da lavoura da mandioca não cobrir os gastos dos agricultores, esta é cultivada pelo fato de ser rústica e de fácil cultivo, ajudar na alimentação da família e no orçamento familiar, além de ser tradicionalmente uma cultura marcante desta microrregião.

De acordo com Almeida (2006), essa preferência pode ser explicada pelo fato de ser uma cultura que desempenha importante papel social como principal fonte de carboidratos para milhões de pessoas, principalmente nos países em desenvolvimento.
Segundo Rosa (2002), a produção de farinha de mandioca é uma atividade de grande importância, não somente pelo aspecto econômico, mas também pelo lado social, visto que ela aumenta as relações sociais entre os membros das famílias (esposa, marido e filhos e parentes próximos) e entre as famílias locais.

Culturas alimentares anuais como a mandioca e o feijāo, tradicionalmente, são destinadas ao consumo familiar e o excedente destinado ao mercado interno estadual, além de, em geral, serem implantadas em sistema de derrubada e queima, aproveitando a fertilidade natural do solo durante um período de dois a três anos.

Dentre as permanentes, a pimenta-do-reino (Piper nigrum) é a espécie mais freqüente, pois está presente na metade dos arranjos identificados. A preferência dos agricultores por esta espécie, pode ser explicada pelo valor de comercialização do produto, pois segundo o IBGE (2002) é uma das principais culturas agrícolas desse município.

O maracujá (Passiflora sp.), que apesar de todos os entraves, associados à doença e conseqüentemente a despesas com agrotóxicos, está presente em 19\% dos arranjos. Isto se deve ao fato de que uma cooperativa local incentiva o plantio desta cultura, visando o mercado de polpas de frutas. No entanto, devido à alta incidência de doenças no maracujá, observada no município estudado, a renda obtida com a produção, nem sempre cobre os gastos com agrotóxicos.

Dentre as fruteiras arbóreas, o cupuaçu (Theobroma grandiflorum), o caju (Anacardium occidentale), o açaí (Euterpe oleracea), a pupunha (Bactris gasipaes) e o coco (Cocus nucifera) são as mais freqüentes nos SAF. Vários autores (Homma et al., 1994; Almeida et al., 2002; Brilhante et al., 2004; Costa, 2006a), encontraram que os SAF de agricultores familiares da Amazônia são compostos, em geral, por espécies frutíferas.

O açaí, a pupunha e o coco são espécies que se adaptam em SAF, em decorrência de possuírem copa aberta, talo ereto, fácil propagação, auto-poda e serem de uso múltiplo (Costa, 2006b).

Em pesquisa realizada por Brilhante et al. (2004) no Estado do Acre, foi constatado que a pupunha, o café (Coffea arabica) e o cupuaçu foram as espécies mais freqüentes nos SAF. De acordo com estes autores, a preferência por estas espécies se deu devido a uma grande expectativa dos agricultores, no que se refere a prospecção de comercialização para esses produtos.

Tanto a graviola (Annona muricata), quanto o urucum (Bixa orellana), ambas estão presente em 12,5\% dos SAF comerciais multiestratificados (Tabela 1). A primeira é cultivada visando o comércio de polpas de frutas, enquanto, o urucum é cultivado devido à comercialização do extrato colorante de seu fruto. Contudo, os agricultores estão eliminando esta última espécie de seus sistemas devido ao baixo rendimento dos frutos. 
Por sua vez, as essências madeireiras nos SAF, são praticamente todas de valor econômico, dentre estas espécies, mogno (Swietenia macrophylla) e o nim indiano (Azadirachta indica), são as mais cultivadas pelos agricultores familiares. A freqüência do mogno, possivelmente é explicada em vistas da divulgação da qualidade e preço de sua madeira a nível regional e internacional. Os agricultores que cultivam o nim indiano, o Tachi (Triplaris surinamensis) e Acacia mangium foram incentivados por instituiçôes públicas, entretanto os mesmos desconhecem o uso destas espécies.

No Continente Africano, a adoção de SAF com espécies madeireiras é maior, isto porque os agricultores familiares comercializam com maior facilidade lenha e carvão (Franzel \& Scherr, 2002a e 2002b; Franzel et al., 2002; Mudhara et al., 2003).

\section{SAF IDENTIFICADOS}

As espécies, anuais (temporárias); semi-perenes, frutíferas e madeireiras (permanentes), são cultivadas em diferentes arranjos, escalonados no tempo e no espaço. Ao todo foram identificados 32 sistemas agroflorestais (Tabela 2). A maioria dos SAF é composta por espécies frutíferas, isto é, 78,12\% possuem pelo menos uma espécie frutífera. As espécies permanentes, com fins madeireiros estão presentes em 50\% dos arranjos.

Tabela 2 - Freqüência de ocorrência dos SAF identificados nas áreas de agricultores familiares de Igarapé-Açu, PA

\begin{tabular}{lll}
\hline SAF & Arranjo & Fr (\%) \\
\hline 1 & Graviola+pimenta-do-reino & 9,4 \\
\hline 2 & Açaí +cupuaçu & 6,3 \\
\hline 3 & Mogno+pimenta-do-reino & 6,3 \\
\hline 4 & $\begin{array}{l}\text { Abacaxi+andiroba+batata-doce+pimenta-de- } \\
\text { cheiro+teça }\end{array}$ & 3,1 \\
\hline 5 & Acacia mangium+pimenta-do-reino+nim+teca+urucum & 3,1 \\
\hline 6 & Acacia mangium+pimenta-do-reino+tachi & 3,1 \\
\hline 7 & Açaí+cacau+caju+cupuaçu+ipê+mogno+piment & 3,1 \\
\hline 8 & Açaí+caju+cupuaçu & 3,1 \\
\hline 9 & $\begin{array}{l}\text { Açaí+cedro+cupuaçu+mandioca+maracujá+sumaú } \\
\text { ma }\end{array}$ & 3,1 \\
\hline 10 & Açaí+pimenta-do-reino & 3,1 \\
\hline 11 & Andiroba+abacate+coco+cupuaçu+feijão+mandioca & 3,1 \\
\hline 12 & Andiroba+cedro+cupuaçu+mamão & 3,1 \\
\hline 13 & Arroz+caju & 3,1 \\
\hline 14 & Bacabi+caju+coco+laranja & 3,1 \\
\hline 15 & Banana+coco+mogno+pimenta-do-reino+Vochysia sp & 3,1 \\
\hline 16 & Banana+cumaru+cupuaçu+pimenta-do-reino+teça & 3,1 \\
\hline & & \\
\hline
\end{tabular}

\begin{tabular}{lll}
\hline 17 & Caju+feijão+muruci+pupunha & 3,1 \\
\hline 18 & Caju+mandioca+muruci+pupunha+urucum & 3,1 \\
\hline 19 & Caju+mandioca+urucum & 3,1 \\
\hline 20 & Coco+maracujá+cupuaçu & 3,1 \\
\hline 21 & $\begin{array}{l}\text { Cupuaçu+feijão+jerimum+mandioca+manga+mogno } \\
\text { +ipê+paricá+pupunha }\end{array}$ & 3,1 \\
\hline 22 & Cupuaçu+maracujá+pupunha & 3,1 \\
\hline 23 & Feijão+coco+pimenta-do-reino & 3,1 \\
\hline 24 & Feijão+limão+nim & 3,1 \\
\hline 25 & Feijão+mandioca+nim+pimenta-do-reino & 3,1 \\
\hline 26 & Feijão+maracujá+nim+pimenta-do-reino+laranja & 3,1 \\
\hline 27 & Feijão+pimenta-do-reino+pupunha & 3,1 \\
\hline 28 & Limão+maracujá+pimenta-do-reino & 3,1 \\
\hline 29 & Mandioca+maracujá+muruci & 3,1 \\
\hline 30 & Mandioca+urucum & 3,1 \\
\hline 31 & Mogno+pimenta-do-reino+pupunha & 3,1 \\
\hline 32 & Nim+pimenta-do-reino & 3,1 \\
\hline
\end{tabular}

Nota: $\operatorname{Fr}(\%)$ : freqüência relativa expressa em porcentagem

Apenas três sistemas (Graviola + pimenta-do-reino; Açaí + cupuaçu; Mogno + pimenta-do-reino) são praticados por mais de um agricultor. Mesmo que tenham sido identificados 32 SAF, isto é, uma média de dois SAF por propriedade, $31,2 \%$ destes foram desenhados ou incentivados por técnicos de instituições públicas, sem que o agricultor tivesse participado na escolha das espécies arbóreas.

Essa diversificação dos SAF permite um maior aproveitamento da área cultivada, ao invés de ser feito o replantio das espécies de um determinado SAF, o agricultor prefere cultivar outras espécies, frutíferas, em geral a banana, de forma a ocupar aquele espaço. Com isso, o agricultor pode obter diferentes produtos do SAF, além de aumentar a diversidade de espécies nos SAF e aperfeiçoar o uso da área destinada a este sistema.

\section{ESPÉCIES DE INTERESSE DO AGRICULTOR}

Dezenove espécies de interesse do agricultor foram identificadas e estavam assim distribuídas: três anuais, e 16 permanentes (Tabela 3).

Dentre as fruteiras, as de maior interesse são: açaí (26,3\%); cupuaçu $(15,8 \%)$; pupunha $(15,8 \%)$; pimenta-do-reino $(15,8 \%)$ para condimento; e nas anuais entram em destaque: mandioca $(21,1 \%)$ e feijāo. $(10,5 \%)$. No que diz respeito às madeireiras, andiroba (Carapa guianensis), mogno (Swietenia macrophylla), teca (Tectona grandis), ucuuba (Virola sp.) são as preferidas deste grupo, com 5,3\% de interesse. 
Tabela 3 - Espécies de interesse dos agricultores familiares da área de estudo.

\begin{tabular}{|c|c|c|c|}
\hline Nome Vulgar & Nome Científico & $\mathrm{Fr}(\%)$ & Finalidade \\
\hline \multicolumn{4}{|l|}{ Temporárias } \\
\hline Mandioca & Manihot esculenta & 21,1 & C \\
\hline Feijão & Vigna sp & 10,5 & $\mathrm{C}, \mathrm{A}$ \\
\hline Macaxeira & Manihot sp & 5,3 & $A, C$ \\
\hline \multicolumn{4}{|l|}{ Permanentes } \\
\hline Açaí & Euterpe oleracea & 26,3 & $A, C$ \\
\hline Cupuaçu & Theobroma grandiflorum & 15,8 & $A, C$ \\
\hline Pupunha & Bactris gasipaes & 15,8 & C \\
\hline Pimenta-do-reino & Piper nigrum & 15,8 & C \\
\hline Laranja & Citrus sinensis & 10,5 & C \\
\hline Acerola & Malpighia glabra & 5,3 & C \\
\hline Algodão & Gossypium hirsutum & 5,3 & C \\
\hline Andiroba & Carapa guianensis & 5,3 & C \\
\hline Bacabi & Oenocarpus minor Mart & 5,3 & $A$ \\
\hline Banana & Musa sp & 5,3 & $A, C$ \\
\hline Coco & Coccus nucifera & 5,3 & C \\
\hline Limão & Citrus sp & 5,3 & C \\
\hline Maracujá & Passiflora sp & 5,3 & C \\
\hline Mogno & Swietenia macrophylla & 5,3 & C \\
\hline Teca & Tectona grandis & 5,3 & C \\
\hline Ucuuba & Virola surinamensis & 5,3 & C \\
\hline
\end{tabular}

Notas: Fr (\%): frequiência relativa expressa em porcentagem A: Autoconsumação; C: Comercialização

Dentre as permanentes, a pimenta-do-reino (Piper nigrum) é a espécie mais freqüente, pois está presente na metade dos arranjos identificados. A preferência dos agricultores por esta espécie, pode ser explicada pelo valor de comercialização do produto, pois segundo o IBGE (2002) é uma das principais culturas agrícolas desse município.

Pando-Moreno e Villalôn-Mendonza (2001) identificaram, no México, 11 espécies arbóreas de interesse do agricultor em cultivá-las em sistemas agroflorestais, em geral, do tipo agrossilvicultural, cujos critérios de seleção das espécies estavam associados ao conhecimento e ao uso múltiplo.

\section{INVENTÁRIO FLORÍSTICO DOS SAF PRODUTIVOS}

\section{COMPOSIÇÃO FLORÍSTICA E ABUNDÂNCIA DOS SAFS}

Ao todo foram inventariados $21 \mathrm{SAFs}$ produtivos nas áreas de agricultores familiares do Município de Igarapé-Açu. Os indivíduos inventariados pertenciam a 18 famílias, 26 gêneros e 28 espécies arbóreas e arbustivas. As famílias Arecaceae e Meliaceae apresentaram maior número de espécies, quatro cada uma (Tabela 4).

Tabela 4 - Abundância e composição florística de 21 sistemas agroflorestais (SAF) estudados em áreas de agricultores familiares de Igarapé-Açu, Pará.

\begin{tabular}{|c|c|c|c|c|}
\hline SAF & $\begin{array}{l}\text { Número de } \\
\text { Famílias }\end{array}$ & $\begin{array}{l}\text { Número de } \\
\text { Gênero }\end{array}$ & $\begin{array}{l}\text { Número de } \\
\text { Espécie }\end{array}$ & Abundância \\
\hline SAF7 & 4 & 4 & 4 & 256 \\
\hline SAF31 & 3 & 3 & 3 & 761 \\
\hline SAF3a & 2 & 2 & 2 & 185 \\
\hline SAF1 & 2 & 2 & 2 & 439 \\
\hline SAF13 & 2 & 2 & 2 & 145 \\
\hline SAF2a & 2 & 2 & 2 & 60 \\
\hline SAF18 & 5 & 5 & 5 & 234 \\
\hline SAF16 & 5 & 5 & 5 & 104 \\
\hline SAF15 & 5 & 5 & 5 & 748 \\
\hline SAF3b & 2 & 2 & 2 & 362 \\
\hline SAF6 & 3 & 3 & 3 & 105 \\
\hline SAF32 & 2 & 2 & 2 & 277 \\
\hline SAF22 & 3 & 3 & 3 & 625 \\
\hline SAF9 & 6 & 6 & 6 & 208 \\
\hline SAF27 & 3 & 3 & 3 & 221 \\
\hline SAF23 & 3 & 3 & 3 & 195 \\
\hline SAF24 & 3 & 3 & 3 & 625 \\
\hline SAF25 & 4 & 4 & 4 & 165 \\
\hline SAF26 & 5 & 5 & 5 & 149 \\
\hline SAF8 & 3 & 3 & 3 & 750 \\
\hline SAF2b & 2 & 2 & 2 & 200 \\
\hline Média & 3 & 3 & 3 & 350 \\
\hline
\end{tabular}

Nota: As letras "a" e "b" indicam que existem mais de um SAF do referido número.

O número de famílias, gênero e espécies variou de dois a seis. Convém ressaltar que, a média de espécies por SAF foi igual três. Além disso, o SAF9 (Tabela 4) constituído por açaí, cedro, cupuaçu, mandioca, maracujá e sumaúma, apresentou maior diversidade de famílias, gêneros e espécies, quando comparado aos demais SAF.

Em se tratando de abundância absoluta a maioria foi observada no SAF31 (761 indivíduos/ha) e a menor no SAF2a (60 indivíduos/ha) (Tabela 4). 


\section{CRESCIMENTO MÉDIO EM ALTURA, DIÂMETROS DA BASE DO CAULE, A ALTURA DO PEITO E DE COPA}

Os SAF avaliados possuem palmeiras (açaí e pupunha) com altura média de $6,3 \mathrm{~m} \pm 0,1 \mathrm{~m}$ e diâmetro médio à altura do peito de $12,4 \mathrm{~cm} \pm 0,2 \mathrm{~cm}$. As espécies arbóreas lenhosas apresentaram altura média igual a $5,8 \mathrm{~m} \pm 0,1 \mathrm{~m}$, diâmetro médio altura do peito de $20,3 \mathrm{~cm} \pm 0,4 \mathrm{~cm}$, diâmetro da base de $11,5 \mathrm{~cm} \pm 0,2 \mathrm{~cm}$ e diâmetro médio de copa de 5,0 $\mathrm{m} \pm 0,87 \mathrm{~m}$.

O cupuaçu (Theobroma grandiflorum) pertencente a família Sterculiaceae foi a espécie frutífera mais cultivada nos sistemas agroflorestais avaliados em Igarapé-Açu. Nestes sistemas, o cupuaçu é associado com várias espécies, tais como: açaí, caju e pupunha.

Os cupuaçuzeiros avaliados apresentaram crescimento médio em altura $3,5 \mathrm{~m}$, de diâmetro da base $12,5 \mathrm{~cm}$. O diâmetro médio de copa, por sua vez, foi igual a $3,6 \mathrm{~m}$ (Tabela 5).

Tabela 5 - Crescimento médio em altura, diâmetro da base / à altura do peito, de copa das espécies mais freqüentes em sistemas agroflorestais de agricultores familiares de Igarapé-Açu, Pará, Brasil.

\begin{tabular}{|c|c|c|c|c|}
\hline Espécie & Altura(m) & $\mathrm{DAP}(\mathrm{cm})$ & $\mathrm{DAB}(\mathrm{cm})$ & $\begin{array}{l}\text { Diâmetro de } \\
\text { copa }(\mathrm{m})\end{array}$ \\
\hline $\begin{array}{l}\text { Açaí (Euterpe } \\
\text { oleracea) }\end{array}$ & $5,8 \pm 0,1$ & $9,9 \pm 0,2$ & & - \\
\hline $\begin{array}{l}\text { Caju (Anacardium } \\
\text { occidentale) }\end{array}$ & $3,4 \pm 0,1$ & & $10,2 \pm 0,3$ & $3,6 \pm 0,08$ \\
\hline $\begin{array}{l}\text { Cupuaçu } \\
\text { (Theobroma } \\
\text { grandiflorum) }\end{array}$ & $3,5 \pm 0,1$ & & $12,5 \pm 0,4$ & $3,6 \pm 0,09$ \\
\hline $\begin{array}{l}\text { Pupunha (Bactris } \\
\text { gasipaes) }\end{array}$ & $6,8 \pm 0,2$ & $14,9 \pm 0,2$ & & - \\
\hline Acacia mangium & $8,8 \pm 0,2$ & $35,2 \pm 0,4$ & & $10,2 \pm 0,12$ \\
\hline $\begin{array}{l}\text { Mogno (Swietenia } \\
\text { macrophylla) }\end{array}$ & $6,8 \pm 0,1$ & $12,6 \pm 0,2$ & & $2,6 \pm 0,06$ \\
\hline $\begin{array}{l}\text { Nim indiano } \\
\text { (Azadirachta } \\
\text { indica) }\end{array}$ & $6,3 \pm 0,1$ & $15,1 \pm 0,3$ & & $5,1 \pm 0,1$ \\
\hline $\begin{array}{l}\text { Teca (Tectona } \\
\text { grandis) }\end{array}$ & $8,3 \pm 0,1$ & $26,4 \pm 0,2$ & & $7,1 \pm 0,08$ \\
\hline
\end{tabular}

$\mathrm{Na}$ floresta nativa, o cupuaçuzeiro pode chegar até $20 \mathrm{~m}$, no entanto, em plantios comerciais costuma ter, em média, $8 \mathrm{~m}$ de altura, sendo que espaçamento ideal para o cultivo do cupuaçuzeiro varia de $5 \mathrm{~m} \mathrm{x} 4 \mathrm{~m}$ e $5 \mathrm{~m} \mathrm{x} 6 \mathrm{~m}$ (Leite $e t$ al., 2006).

Em se tratando do caju (Anacardium occidentale), na Tabela 5 é observado que o crescimento médio em altura é de $3,4 \mathrm{~m}$, de diâmetro de $10,2 \mathrm{~cm}$, com diâmetro de copa médio de 3,6 m.
De acordo com IAC (2006a) esta espécie permite que durante os primeiros cinco anos de plantio, seja cultivada junto a outras culturas, preferencialmente leguminosas, desde que o espaçamento entre os indivíduos de cajuzeiros seja de pelo menos $7 \mathrm{~m} \mathrm{x} 7 \mathrm{~m}$.

Nos SAF identificados, o açaí é outra espécie bastante cultivada. Os indivíduos avaliados apresentaram crescimento médio de altura de $5,8 \mathrm{~m}$ e de diâmetro altura do peito de $9,9 \mathrm{~cm}$. As touceiras têm em média dois perfilhos e os estipes apresentam, em média, um cacho.

Os dados deste trabalho, referentes ao DAP, indicam que os indivíduos de açaí, nos SAF avaliados, poderiam ser manejados para a produção de palmito, uma vez que, segundo IAC (2006b), o diâmetro mínimo de corte dessa palmeira para esse fim é $10 \mathrm{~cm}$.

No entanto, os agricultores familiares, que implantaram esta espécie, visam, sobretudo, a colheita de frutos para a venda, apesar de que até o momento desta pesquisa, a produção tenha sido destinada a própria subsistência. Cabe mencionar que esta espécie tem sido bastante cultivada na Amazônia, uma vez que segundo Yuyama et al. (2002), devido seu alto valor energético, e por este apresentar valores consideráveis de fibra alimentar, o interesse por esta espécie vem aumentando cada vez mais no mercado nacional.

Em se tratando da pupunha, os indivíduos de pupunha, tiveram crescimento médio em altura de $6,8 \mathrm{~m}$ e diâmetro médio de $14,9 \mathrm{~cm}$. Vale mencionar que, em média, cada touceira de pupunheira continha três perfilhos.

O desempemho de crescimento das pupunheiras nos SAF de Igarapé-Açú, em média cinco anos de idade, se assemelham a outros trabalhos realizados no Estado do Pará. Pesquisa realizada por Ribeiro (1997), mostra que as pupunheiras quando consorciadas com diferentes variedades de bananeiras, com aproximadamente três anos de idade, tiveram um crescimento médio em altura de 6,44 $\mathrm{m}$ e de DAP igual a $16,21 \mathrm{~cm}$. Por outro lado, Mota (1997) avaliando o crescimento inicial das pupunheiras em SAF, aos dois anos após o plantio, pôde observar que o crescimento médio em altura foi de $90 \mathrm{~cm}$.

Yuyama \& Silva (2003) estudando o comportamento inicial de pupunheiras, em monocultivos e em SAF, observaram que os indivíduos avaliados obtiveram rápido crescimento, com alturas variando de $3,7 \mathrm{~m}$ a $6,0 \mathrm{~m}$ e, DAP de $34,4 \mathrm{~cm}$ a $65,5 \mathrm{~cm}$. De acordo com esses autores, a melhor taxa de crescimento ocorreu com pupunheiras consorciadas com amendoim e a menor com pupunheiras cultivadas na forma de monocultivos e com arroz.

Estudos realizados com a pupunheira mostram que o sistema radicular desta palmeira é bastante superficial (IAC, 2006c), podendo gerar competição com outras espécies. A 
exemplo disso em Igarapé-Açu foi observado que a pupunha quando cultivada com feijão, caju e muruci, afetou o crescimento destas últimas espécies.

No que diz respeito às espécies madeireiras, o mogno brasileiro (Swietenia macrophylla), uma Meliácea de grande valor comercial no mercado nacional e internacional, foi as mais cultivadas nos SAF avaliados em Igarapé-Açu. Esta espécie apresentou crescimento médio em altura de $6,8 \mathrm{~m}$ e de DAP de $12,6 \mathrm{~cm}$. No que se refere o diâmetro de copa, os indivíduos apresentaram em média $2,6 \mathrm{~m}$.

Quando se compara os resultados obtidos neste estudo com outros trabalhos realizados com mogno, é possível observar que esta espécie apresenta bom desempenho em SAF. Em sistema agrossilvipastoril de altos insumos, por exemplo, o mogno atingiu $10,2 \mathrm{~m}$ de altura e $12,3 \mathrm{~cm}$ de diâmetro, enquanto que nos de baixos insumos a média foi de $8,9 \mathrm{~m}$ de altura e 11,9 cm de diâmetro (MCT, 2006).

Em trabalho realizado por Guimarães Neto et al., (2004), o mogno apresentou, aos 40 meses após o plantio, crescimento médio em altura de $3,45 \mathrm{~m}$ quando cultivado em monocultivo e, 2,28 m quando associado com eucalipto.

Em associação com guariroba (Syagrus oleracea), palmeira típica do cerrado do Brasil, o mogno aos 3,5 anos, teve crescimento médio de altura de 5,1 m e DAP de 7,6 $\mathrm{cm}$, enquanto em monocultivo, esta meliácea apresentou crescimento médio em altura de $3,8 \mathrm{~m}$ e DAP de $5,0 \mathrm{~cm}$ (Melo, 2003).

Outra espécie madeireira que merece ser destacada no presente estudo é o nim indiano, freqüente em quase 16\% dos SAF produtivos. Em Igarapé-Açu, esta espécie apresentou altura média de $6,3 \mathrm{~m}$ e DAP médio de $15 \mathrm{~cm}$, e diâmetro médio de copa de $5,1 \mathrm{~m}$.

Neste município, os indivíduos de nim indiano estão plantados sob diferentes espaçamentos, tais como: $4 \times 4 \mathrm{~m}$; $6 \times 6 \mathrm{~m} ; 7,8 \times 7,8 \mathrm{~m}$ e $8,2 \times 8,2 \mathrm{~m}$. Vale mencionar que para fins energéticos o espaçamento recomendado é de $2 \times 2 \mathrm{~m}$ ou de 4 x 4 m (Neves \& Nogueira, 1996).

Em associação com guariroba, o nim indiano, aos 3,5 anos, teve crescimento médio de altura de 3,2 m e DAP de $5,9 \mathrm{~cm}$, enquanto que cultivado em monocultivo, segundo Melo (2003), esta meliaceae apresentou crescimento inferior em altura $(2,4 \mathrm{~m})$ e em DAP $(3,8 \mathrm{~cm})$.

A teca (Tectona grandis L.f.) pertencente à família Verbenaceae é uma espécie madeireira exótica cultivada nos SAF de Igarapé-Açu. Neste estudo, a teca teve um rápido crescimento, pois aos sete anos de idade os indivíduos apresentaram altura média de $8,3 \mathrm{~m}$, DAP médio de $26,4 \mathrm{~cm}$ e diâmetro médio de copa igual a 7,1 m.

Segundo Angeli \& Stape (2003), apesar da espécie ser cultivada apenas em regiōes tropicais, sua madeira é muito procurada (principalmente) no continente europeu, onde o preço por metro cúbico supera o do próprio mogno.

Acacia mangium é outra espécie exótica cultivada em SAF de Igarapé-Açu. Esta leguminosa apresenta rápido crescimento, capacidade de melhorar a fertilidade do solo, boa adaptação às condições pedoclimáticas difíceis, enraizaimento profundo, resposta à insolação e baixo nível de nutrientes, ela tem sido indicada para recuperação de áreas degradadas (Lauriola et al., 2006).

Nos SAF de Igarapé-Açu, esta espécie, aos sete anos de idade, apresentou crescimento médio em altura de $8,8 \mathrm{~m}$, DAP médio de $35,2 \mathrm{~cm}$ e diâmetro médio de copa de 10,2 m.

Devido ao espaçamento adotado e ao tamanho de sua copa, esta espécie pode provocar sombreamento excessivo sobre as culturas anuais e semi-perenes. A exemplo disso, em Igarapé-Açu, foi observado que pimenta-do-reino associada a esta espécie foi bastante prejudicada pelo sombreamento desta leguminosa, mesmo o agricultor adotando espaçamento de $20 \mathrm{~m} \times 9,5 \mathrm{~m}$.

Estes dados indicam a necessidade de se fazer uma seleção mais rigorosa no que se refere à escolha das espécies que irão compor os sistemas agroflorestais, do espaçamento a ser adotado em áreas de agricultores familiares na Região Amazônica.

\section{IMPLANTAÇÃO E MANEJO DOS SAF}

Em geral, o preparo das áreas destinadas aos $\mathrm{SAF}$ se dá por meio de derruba e queima e de forma mecanizada com uso de trator e grades aradoras. Do total de agricultores familiares que adotaram SAF, mais de 50\% prepararam suas áreas com grades aradoras. $\mathrm{O}$ preparo de área mecanizado tem se intensificado em decorrência da diminuição do tempo de pousio e da baixa fertilidade do solo. Vale ressaltar que nenhum agricultor fez o preparo totalmente mecanizado, devido à falta de máquinas e $\mathrm{o}$ alto custo com o aluguel. $\mathrm{O}$ uso de maquinário no preparo de área ocorre, em geral, quando os SAF são resultantes de projetos financiados ou, quando existe boa parceria entre a prefeitura e as organizações comunitárias locais.

A adubação de arranque ou de pré-plantio é realizada com adubo químico: nitrogênio, fósforo e potássio em diferentes formulaçōes, ou com adubos orgânicos como: esterco de galinha ou de gado, casca de mandioca e de feijāo, entre outros.

O plantio de um modo geral é feito manualmente. No caso do componente arbóreo, $81,2 \%$ dos agricultores usam mudas, $6,2 \%$ fazem a semeadura direta e os demais combinam os métodos. O semeio direto é empregado para as espécies frutíferas: açaí, cacau e cupuaçu. O plantio das espécies anuais e das semi-perenes é feito de forma tradicional.

A capina e a roçagem são os tratos culturais mais freqüentes nos SAF implantados no município de estudo. A capina é 
feita de forma manual, mecanizada e química.. O uso de herbicida foi verificado em $68,7 \%$ das propriedades com SAF e a eliminação das plantas daninhas é realizada a cada dois meses. Este intervalo de tempo varia conforme o nível de infestação, da quantidade de mão-de-obra familiar, bem como dos recursos financeiros disponíveis, para contratar mãode-obra extra-familiar. Além destes tratos culturais, 12,5\% fazem poda e desbaste de espécies madeireiras e frutíferas dos SAF. Estes tratos visam, sobretudo, manipular o microclima contidas nos SAF, e com isso evitar a competição por radiação solar, água e nutrientes.

O controle de pragas e doenças é feito com o uso de agrotóxicos, sendo $50 \%$ com fungicidas e $18,7 \%$ inseticidas. As enfermidades mais freqüentes nos SAF são: virose do maracujá; mela da pimenta; vassoura de bruxa no cupuaçu e broca dos frutos de graviola. Somente 33,3\% dos SAF implantados não apresentaram infestação de pragas e doença.

Todas as atividades inerentes a implantação e ao manejo dos SAF tendem a seguir o calendário agrícola local, o qual está relacionado com o clima predominante no município. Assim, a limpeza e o preparo da área ocorrem no período menos chuvoso, tendo início no mês de julho, indo até o mês de novembro.

Em se tratando do plantio, esta atividade tem início em dezembro e termina em maio, coincidindo com o término do período chuvoso. A adubação, por sua vez, é realizada nos meses de janeiro a fevereiro (adubação de várias espécies) e maio (adubação do feijāo).

A capina, poda e desbaste são realizados em diversos períodos do ano, de acordo com as necessidades de manutenção do SAF. A colheita dos produtos gerados por estes sistemas ocorre durante quase todo o ano. Isto se deve ao fato dos plantios serem diversificados, permitindo ao agricultor colher diferentes produtos.

\section{CONCLUSÃO}

As espécies pimenta-do-reino, mandioca, feijão, cupuaçu, caju, açaí, pupunha, mogno e o nim indiano são as mais cultivadas pelos agricultores familiares de Igarapé-Açu.

Os sistemas agroflorestais praticados pelos agricultores são pouco diversificados, apresentando baixos valores de abundância.

Os SAF são manejados, na sua maioria, de forma tradicional e com baixo nível tecnológico.

\section{BIBLIOGRAFIA CITADA}

Almeida, C.M.V.C.; Müller, M.W.; Sena-Gomes, A.R.; Matos, P.G.G. 2002. Sistemas agroflorestais com cacaueiro como alternativa sustentável para uso em áreas desmatadas, no Estado de Rondônia, Brasil. Agrotrópica, 14(3): 109-120.

Almeida, J. 2006. Mandioca na alimentação animal. Brasil: Agronline, (http://www.agronline.com.br/artigos/artigo. php?id=189\&pg=1\&n=5). Acesso: 01/02/2006.

Angeli, A.; Stape, J.L. 2003. Identificação de espécies florestais: Teca (Tectona grandis). Disponível em http://www.ipef.br/ identificacao/tectona.grandis.asp. Acesso: 08/09/2003.

Bentes-Gama, M.M. 2003. Análise técnica e econômica de sistemas agroflorestais em Machadinho D’Oeste, Rondônia. Tese de Doutorado, Universidade Federal de Viçosa, Viçosa, MG. $115 \mathrm{pp}$.

Brilhante, M.O.; Rodrigues, F.Q.; Brilhante, N.A.; Penereiro, F.M.; Ludewigs, T.; Flores, A.L.; Souza, J.F. 2004. Avaliação da sustentabilidade de sistemas agroflorestais no Vale do Juruá, Estado do Acre. In: Congresso Brasileiro de Sistemas Agroflorestais, 5, Anais... EMBRAPA Florestas, Curitiba, Paraná.

Costa, N. L. 2006a. Alternativas agroflorestais para os sistemas de produção agrícola e pecuário de Rondônia. Disponível em http://www.cpafro.embrapa.br/embrapa/Artigos/Altern_agr. html. Acesso em: 01/02/2006.

Costa, N.L. 2006b. Sistemas produtivos do Amapá. Brasil Disponível em http://www.agronline.com.br/artigos/artigo. php?id=49\&pg=1\&n=3. Acessado: 01/02/2006.

Franke, I.L.; Lunz, A.M.P.; Amaral, E.F. 1998. Caracterização sócioeconômica dos agricultores do grupo Nova União, Senador Guiomard Santos, Acre: ênfase para implantação de sistemas agroflorestais. EMBRAPA-CPAF/AC, Rio Branco, Acre. Embrapa-CPAF/AC. Documentos, 33. 39pp.

Franzel, S; Scherr, S.J. 2002a. Introduction. In: Franzel, S; Scherr, S.J. (ed) Trees on the farm: assessing the adoption potential of Agroforestry practices in Africa. CABI/ICRAF, New York. 197pp.

Franzel, S; Scherr, S.J. 2002b. Assessing the adoption potential: lessons learned and future directions. In: Franzel, S; Scherr, S. J. (ed) Trees on the farm: assessing the adoption potential of Agroforestry practices in Africa: CABI/ICRAF, New York. 197pp.

Franzel, S.; Phiri, D.; Kwesiga, F. 2002. Assessing the adoption potential of improved fallows in Eastern Zambia. In: Franzel, S; Scherr, S.J. (ed) Trees on the farm: assessing the adoption potential of Agroforestry practices in Africa. CABI/ICRAF, New York.197pp.

Guimarães Neto, A.B.; Felfili, J.M.; Silva, G.F.; Mazzei, L.; Fagg, C.W.; Nogueira, P.E. 2004. Avaliação do plantio homogêneo de mogno, Swietenia macrophylla King, em comparação com o plantio consorciado com Eucalyptus urophylla S. T. Blake, após 40 meses de idade. Revista Arvore, 28(6): 777-784. 
Homma, A.K.O.; Walter, R.T.; Carvalho, R.A.; Ferreira, C.A.P.; Conto, A.J.; Santos, A.I.M. 1994. Dinâmica dos sistemas agroflorestais: o caso dos agricultores nipo-brasileiros em ToméAçu, Pará. In: Congresso Brasileiro de Sistemas Agroflorestais, 1, Resumos... EMBRAPA-CNPF, Colombo, Paraná. p. 51-61.

IAC - Instituto Agronômico de Campinas. Frutíferas: caju (Anacardium occidentale L.) Disponível em http://www.iac. sp.gov.br/Centros/centro\%20de\%20fruticultura. Acesso: 02/02/2006.

IAC - Instituto Agronômico de Campinas. Frutíferas: açaí (Euterpe oleracea Mart.) Disponível em http://www.iac.sp.gov.br/Centros/ centro\%20de\%20fruticultura. Acesso: 02/02/2006.

IAC - Instituto Agronômico de Campinas. Frutíferas: pupunha (Bactris gasipaes H.B.K.). Disponível em: http://www.iac. sp.gov.br/Centros/centro\%20de\%20fruticultura. Acesso: 02/02/2006.

IBGE - Instituto Brasileiro de Geografia e Estatística. 2002. Produçāo Agrícola Municipal. IBGE, Rio de Janeiro.

Lauriola, V.; Barbosa, R.I.; Nascimento Filho, H.R. 2006. Nota preliminar sobre impactos das plantaçôes de Acacia mangium Wild. sobre terras e populaçōes indígenas de Roraima. Disponível em http://agroeco.inpa.gov.br/reinaldo/RIBarbosa_ProdCient_ Usu_Visitantes /2002AcaciaNotaINPA_Indios.pdf). Acesso: 02/02/2006.

Leite, J.B.V.; Lins, R.D.; Vieira, E.S. 2006. Fruteiras tropicais para consórcios agrícolas no sul da Bahia. Disponível em http://www. ceplac.gov.br/radar/Artigos/artigo4.htm. Acesso: 01/02/2006.

MCT- Ministério da Ciência e Tecnologia, 2006. Recuperação de áreas de pastagens abandonadas e degradadas através de sistemas agroflorestais na Amazônia Ocidental. Disponível em http:// www.mct.gov.br/prog/ppg7/projetos/proj991.pdf. Acesso: $09 / 02 / 2006$.

Melo, J. T. 2003. Cultivo de guariroba (Syagrus oleracea Becc) em sistemas consorciados com espécies florestais no cerrado. EMBRAPA Cerrados, Planaltina. Comunicado técnico, 97. 2pp.

Mota, M.S.S. 1997. Desenvolvimento inicial de espécies arbóreas em sistemas agroflorestais no Município de Manacapuru-AM.. Instituto Nacional de Pesquisas da Amazônia/Fundação Universidade do Amazonas, Manaus, Amazonas. 91pp.

Mudhara, M.; Hilderbrand, P.E.; Nair, P.K.R. 2003. Potential for adoption of Sesbania sesban improved fallows in Zimbabwe: a linear programming-based case study of small-scale farmers. Agroforestry Systems, 59(3): 307-315.

Neves, B.P.; Nogueira, J.C.M. 1996. Cultivo e utilização do nim indiano (Azadirachta indica A. Juss.). EMBRAPA/CNPAF, Goiânia, Goiás, 32pp.
Pando-Moreno, M.; Villatôn-Mendonza, H. 2001. Potential agroforestry species identified in the Tamaulipan thornscrub of north-eastern México. Agroforestry Today, 13(1-2): 14-15.

Ribeiro, G. D. 1997. Incremento inicial de espécies arbóreas usadas em sistemas agroflorestais para sombreamento definitivo no cultivo do cupuaçuzeiro (Theobroma grandiflorum Schun). Dissertação de Mestrado, Faculdade de Ciências Agrárias do Pará, Belém, PA. $150 \mathrm{pp}$.

Rosa, L.S. 2002. Limites e possibilidades do uso sustentável dos produtos madeireiros e não madeireiros na Amazônia brasileira: o caso dos pequenos agricultores da Vila Boa Esperança, em Moju, no Estado do Pará. Tese de Doutorado. Universidade Federal do Pará/Núcleo de Altos Estudos da Amazônia, Belém, PA. 304pp.

Yuyama, K.; Silva, F. M. S. 2003. Desenvolvimento inicial da pupunheira em monocultivo e intercalado com culturas anuais. Horticultura Brasileira, 21(1): 15-19.

Yuyama, L.K.O.; Aguiar, J.P.L.; Melo, T.; Barros, S.E.; Silva-Filho, D.F.; Yuyama, K.; Fávaro, D.I.T.; Vasconcellos, M.B.A.; Pimentel, S.A.; Badolato, E.S.G. 2002. Açaí (Euterpe oleracea Mart): qual seu potencial nutricional? Anais XVIII Congresso Brasileiro de Fruticultura. CD-rom.

Recebido em 29/12/2006

Aceito em 16/08/2007

\section{ANEXO 1}

MODELO DE ENTREVISTA USADA NA COLETA DE DADOS SOCIOECONÔMICOS

Nome:

Comunidade:

Idade:

Onde nasceu?

Nível de instrução?

Qual a origem dos recursos financeiros empregados nos SAF?

Contou com ajuda de assistência técnica?

Quais as espécies do SAF comercial?

Quais espécies $0 \mathrm{Sr}$. ainda tem interesse em plantar?

Como é feita a implantação do SAF?

Como as atividades são distribuídas ao longo do ano?

Quais são as despesas com o SAF? 
